\title{
$\checkmark$ Research Square \\ Primary Ovarian Leiomyoma: A common tumor in rare location and report of eight cases
}

\section{wu zaigui}

zhejiang university https://orcid.org/0000-0003-4033-872X

Dong minyue ( $\nabla$ dongmy@zju.edu.cn )

womens'hospital ,zhejiang university,school of medicine

\section{Research}

Keywords: leiomyoma, ovary, solid tumor, pelvic mass, case report

Posted Date: March 24th, 2020

DOI: https://doi.org/10.21203/rs.3.rs-18276/v1

License: (c) (i) This work is licensed under a Creative Commons Attribution 4.0 International License. Read Full License 


\section{Abstract}

Background: Ovarian Leiomyoma accounts only for 0.5 to $1 \%$ of all benign ovarian tumors. Here we present a series of eight patients over a six-year period(2012-2018). The clinico-pathological features, diagnosis and management were discussed.

Methods: We had experienced eight cases of ovarian leiomyoma. The clinical features,pathologic findings, diagnosis, treatment were reviewed.

Results: The mean age of these patients was 38.5 years. The majority of these patients may be asymptomatic and usually diagnosed incidentally during pelvic examination or pathologic examination after surgery. Six cases presented only with pelvic mass sized from 2 to $20 \mathrm{~cm}$ and even some patients persisted for more than twenty years while the other two were diagnosed due to four years of primary infertile or three months of irregular vagina bleeding. Three patients coincident with uterine leiomyoma while the others not. Three had ovarian leiomyoma degenerated and one case had a evidence of atypical $4 / 10$.

Conclusions : ovarian leiomyoma was very rare but it should be considered in the diagnosis of pelvic or ovarian solid masses. Magnetic resonance imaging was provital in its different diagnose while fast frozen pathology during operation was very necessary for its surgical decision. A proper surgical decision should be made according to patients age.

\section{Background}

Leiomyoma is one of the rarest ovarian benign tumors,accounting for $0.5-1 \%$ overall[1]. Sine the first case was described in 1862[2], less than sixty cases had been reported so far and the overwhelming of them were case reports with or without literature review as summarized in Table 1. The age of reported cases ranged from 17 to 79 years old and most of them were small in size,asymptomatic and diagnosed incidentally during routine pelvic examination, at surgery or even at autopsy[3, 4].Few cases can also manifest with lower abdominal pain[5], ascites[6],pelvic mass,elevated cancer antigen 125(CA125) or Meigs' syndrome[4, 7]. They occurred in unilateral ovary mostly while bilateral ovarian leiomyoma were mainly reported in young patients aged 16 to 25 and no has been reported in patients $>35$ years old[5]. Due to its rarity and its similarities to pelvic solid mass, the ovarian leiomyoma was rarely diagnosed preoperatively, and thus the purpose of this paper was to summarize and analyze the clinical data of these ovarian leiomyoma patients during the recent six years along with a review of the literature with all cases to guide the clinical practice.

\section{Methods}

A six-year retrospective study of primary ovarian leiomyoma diagnosed in the Pathology Department of Women's Hospital, Zhejiang University School of Medicine was carried out during year 2012-2018. The 
data were collected mainly by searching on medical records and department of pathology databases. The clinico-pathological features, diagnosis and management were discussed.

\section{Results}

Ovarian leiomyoma was noted in eight cases. The mean age at presentation was 38.5 years with the youngest 17 and the oldest 65 . Pelvic mass was the most common presenting sign(6/8 cases)(Fig. 1,2), while one case presented with four years of primary infertile and the other presented with three months of irregular vagina bleeding. Duration of signs ranged from 1 month to 20 years. The level of CA125 was all in normal range and no patient was diagnosed with ovarian leiomyoma before operation. The oldest two had bilateral salpingo-oophorectomy with or without hysterectomy and the rest of them all had myomectomy. These tumor sized from 2 to $20 \mathrm{~cm}$ and most of them come from one side of the ovaries except one from the left ovarian inherent ligament. Accidented surface with or without vascular engorgement was also found in these tumors and the youngest patient even had $100 \mathrm{ml}$ ascites who was proved to have nuclear division(4/10)(Fig. 3). Leiomyoma degeneration such as hyaline and calcification could also be seen and frozen section during operation contributed to its nature diagnoses or differentiating benign from malignant tumors. Clinical details of the cases are summarized in Table 1 and their macro and/or microscopic features were summarized in Table 2.

\section{Discussion}

Leiomyoma arising from ovary was considered a rare type of solid benign tumor and it could happened to people of all ages, but nearly eighty percent of them occurred in pre-menopausal women[43]. Our department was one of the largest top three specialized hospitals in China and the total number of gynecological surgery was about 17000-20000 per year,while only 8 patients were diagnosed with ovarian leiomyoma during the past six years. The youngest pediatric girl aged only 17,4 fertile and 2 premenopausal women while the other one had been diagnosed 20 years ago when she was 45 . Ovarian leiomyoma usually sized millimeters or a few centimeters and rarely exceeded $3 \mathrm{~cm}$ in diameter meanwhile both ovaries had the same morbidity[44]. Tumor diameter of our cases ranged from 2 to $20 \mathrm{~cm}$ which mainly measured $6-8 \mathrm{~cm}$ that can be easily visible by ultrasound. Just because of their small size, the majority of them were usually asymptomatic and incidentally found when having pelvic examination or surgery for oophorectomy.However,the symptoms such as pelvic pain,abnormal uterine bleeding,constipation and frequent urination were associated with tumor size [45, 46]. Literature had also revealed the relationship between ovarian leiomyoma and infertile[47].All our cases had normal CA125 level, the pediatric girl was diagnosed for menstrual disorder with ascites $100 \mathrm{ml}$ and another one was diagnosed for four years of primary infertile.Rare symptoms including Meigs' syndrome, elevated T level and virilization, abnormal menstruation,urinary symptoms, appendicitis-like symptoms, paraneoplastic syndrome and acute abdomen caused by torsion had also been reported as summarized in Table 3 .

To date, the histological origin of ovarian leiomyoma had not been excluded. Some studies had stated that it possible originated from smooth muscle in ovarian hilar blood vessel, ovarian ligament,ovarian 
stroma,mature cystic teratomas and the wall of mucinous cystic tumour and so on[48], while the most accepted one was that it arised from the smooth muscle of the ovarian ligament where they enter the ovary from the ovary vascular smooth muscle[49]. It could be implied from the enlarged ovarian ligament of our tissue photo. They frequently accompanied with other ipsilateral or contralateral ovarian lesions such as endometriotic cycst [49]although only one patient had contralateral ovarian follicular cycst in present report, thus careful exploration for both ovary was very necessary.

Strictly speaking, primary ovarian leiomyoma had to be entirely within the ovary with no similar lesions in the uterus or elsewhere[50]. However, literature had reported that about eighty percent cases accompanied with uterine leiomyomas[48]. Without exception,three patients aged more than fifty also had multiple uterine leiomyomas. As reported in the literature, leiomyoma degeneration such as hyaline and calcification could also be seen especially in larger tumors,even nuclear mitosis was observed in the pediatric girl(4/10HPF). By literature review, there were five reports revealing abnormal histologic features such as areas of myxoid stroma, atypical leiomyoma, nuclear pleomorphism, mitotic avtivity and nuclear enlargement in ovarian leiomyoma. Thus frozen section and immunohistochemistry could help in its right diagnose and making decision for surgical approach. Though 4 mitosis could be found in very 10 high power field (HPF) in case 5(in Fig. 3), she had an ovary-preserving surgery for adolescence with 2 years no recurrence so far.

When diagnosing ovarian leiomyoma, it should be distinguished from sex-cord stromal tumors including ovarian fibroma,thecoma, leiomyosarcomas while uterine leiomyomas parasiting on the ovary should also be considered. Intra-operative immunohistochemical analysis and frozen section were very helpful in its right diagnosis and surgical decision-making. It would be better if a definite diagnosis could be made before surgery. The majority of our cases had been diagnosed with sex-cord stromal tumors and seldom had a correct diagnosis before operation as showed in Table 1 which was in accordance with the existing literature. The imaging features of ovarian leiomyoma had seldom been described due to its rarity,there were few literatures reporting that intravenous administration of Gd-DTPA and the supplying vessels arising directing from the myometrium as a flow void could both contribute to the differentiation of it from uterine leiomyomas. A good example of this was case 8( in Fig. 1, 2) who had both right ovarian leiomyoma and left uterine subserous leiomyomas. On axial diffusion-weighted image(TR/TE: $4000 / 72.4 \mathrm{~ms}, \mathrm{~b}$ value $=500 \mathrm{~s} / \mathrm{mm} 2$ ) the two masses showed the same intermediate signal intensity. On axial fat-saturated T2-weighted(TR/TE:3020/70.5 ms)image, the signal intensity of the left mass was continued with the myometrium while the right mass was well-circumscribed and sharply demarcated from the uterus. On sagital or axial T1-weighted with gadolinium administration(TR/TE:3.9/1.7 ms) the left mass showed low intensity identical to the uterus myometrium and flow voids could only be seen in left uterine subserous leiomyomas. Although these tumors were benign and rare of them had abnormal histologic features, radical surgeries were usually done for their complete removal because the ovary might become almost completely absorbed by the tumor or just persist portions[50]. A common surgical approach was salpingo-oophorectomy or an oophorectomy with or without hysterectomy,but an ovarypreserving surgery should be suggested in young and fertility-sparing women[51]. 


\section{Conclusions}

Primary ovarian leiomyoma was very rare in clinic and should be considered in the differential diagnosis of ovary solid tumors and subserous myoma .Magnetic resonance imaging was provital in its definite diagnose before operation while fast frozen pathology during operation was very necessary for its surgical decision. Hysterectomy in conjunction with bilateral salpingo-oophorectomy were preferred in middle-aged to elderly patients but an ovary-preserving surgery should be considered in young and childbearing patients.

\section{Abbreviations}

CA125: cancer antigen 125 ;USG: ultrasonography ;CT: computer tomography;MRI: magnetic resonance imagine

\section{Declarations}

\section{Authors' contributions}

WZG collected the clinical data, analysis these data and drafted the manuscript. DMY helped to draft the manuscript and revised the manuscript. All authors read and approved the final manuscript.

\section{Funding}

This study was supported by the Zhejiang provincial Natural Science Foundation of China(Q19H040050) and Zhejiang provincial Science and Technology Plan projects (2019KY431). Both the two funding body played a role in designing the study and writing the manuscript.

\section{Competing interests.}

The authors declare that they have no competing interests.

\section{Consent for publication}

Written informed consent has been obtained from all the cases or her guardian of 17 years old for publication of this paper report.The authors declare that they have no competing interests.

\section{Ethics approval and consent to participate}

This research conformed to the provisions of the Declaration of Helsinki and was approved by the ethics committee of Women's hospital Zhejiang University(No 2019026). The patients were informed and provided her written informed consent.

\section{Availability of data and materials}


The deta-sets used and /or analyzed during the current study are available from the authors on reasonable request.

\section{Acknowledgements}

Not applicable

\section{References}

[1] R. Agrawal, M. Kumar, L. Agrawal, K.K. Agrawal. A huge primary ovarian leiomyoma with degenerative changes-an unusual. J Clin Diagn Res. 7 (2013), 1152-1154.

[2] G. Tsalacopoulos, A.J. Tiltman. Leiomyoma of the ovary. A report of 3 cases. S Afr Med J. 59 (1981), 574-575.

[3] S.C. Lim, H.J. Jeon. Bilateral primary ovarian leiomyoma in a young woman: case report and literature review. GYNECOL ONCOL. 95 (2004), 733-735.

[4] M. Kurai, T. Shiozawa, H. Noguchi, I. Konishi. Leiomyoma of the ovary presenting with Meigs' syndrome. J Obstet Gynaecol Res. 31 (2005), 257-262.

[5] N. Khaffaf, H. Khaffaf, S. Wuketich. Giant ovarian leiomyoma as a rare cause of acute abdomen and hydronephrosis. OBSTET GYNECOL. 87 (1996), 872-873.

[6] J.T. Van Winter, C.R. Stanhope. Giant ovarian leiomyoma associated with ascites and polymyositis. OBSTET GYNECOL. 80 (1992), 560-563.

[7] P. Rajabi, M. Hani, M. Bagheri, F. Mirzadeh. Large ovarian leiomyoma in young woman. Adv Biomed Res. 3 (2014), 88.

[8] M. Kurai, T. Shiozawa, H. Noguchi, I. Konishi. Leiomyoma of the ovary presenting with Meigs' syndrome. J Obstet Gynaecol Res. 31 (2005), 257-262.

[9] J.T. Van Winter, C.R. Stanhope. Giant ovarian leiomyoma associated with ascites and polymyositis. OBSTET GYNECOL. 80 (1992), 560-563.

[10] E. Erdemoglu, M. Kamaci, I. Bayram, A. Guler, S.H. Guler. Primary giant leiomyoma of the ovary-case report. EUR J GYNAECOL ONCOL. 27 (2006), 634-635.

[11] K.R. Prasad, C. Aruna, D.A. Saheb. Primary leiomyoma of ovary. Indian J Med Sci. 47 (1993), 39-41.

[12] O. Carpen, N. Simberg, H. Sasano, E. Saksela. Virilizing ovarian leiomyoma: androgen production by lining stromal cells. Acta Obstet Gynecol Scand. 75 (1996), 72-76. 
[13] J.M. Parish, E.G. Lufkin, R.A. Lee, T.A. Gaffey. Ovarian leiomyoma with hilus cell hyperplasia that caused virilization. MAYO CLIN PROC. 59 (1984), 275-277.

[14] A. Moulla, N. Magdy, M. El-Bahrawy. Ovarian leiomyoma with myxoid stroma. Pathologica. 109 (2017), 389-391.

[15] S. Mallya, I.A. MacFarlane, W. Taylor, C. van Heyningen. Thecal cell reaction associated with an ovarian leiomyoma and presenting with virilization. GYNECOL ENDOCRINOL. 4 (1990), 271-276.

[16] Q.M. Wang, Y. Zhao, Y. Ma, L.T. Yao, X. Han. One case report of giant atypical leiomyoma of the ovary. Medicine (Baltimore). 97 (2018), e12526.

[17] E.U. Emovon, D.J. Cahill, L.A. Joels, M.H. Stegmann. Bilateral primary ovarian leiomyoma: a rare cause of ovarian tumour in a young woman. J OBSTET GYNAECOL. 19 (1999), 676.

[18] A. Abdel-Gadir, N.D. Francis, O.O. Oyawoye, B.P. Chander. Secondary amenorrhoea with high inhibin B level caused by parasitic ovarian leiomyoma. GYNECOL ENDOCRINOL. 26 (2010), 93-95.

[19] S. Erkaya, B. Kutlay, D. Uygur, F. Kara, A. Tezer. Primary ovarian leiomyoma in a postmenopausal woman. Acta Obstet Gynecol Scand. 79 (2000), 79-87.

[20] E.E. Ozcimen, M. Oktem, H.B. Zeyneloglu, B.H. Ozdemir, E. Kuscu. Primary leiomyoma of the ovary in a young woman: literature review and report of a case. EUR J GYNAECOL ONCOL. 27 (2006), 310-312.

[21] N.R. Blue, J.C. Felix, J. Jaque. Primary ovarian leiomyoma in a premenarchal adolescent: first reported case. J Pediatr Adolesc Gynecol. 27 (2014), e87-e88.

[22] V.C. Lema, A.N. Massinde, P.F. Rambau, E. Ndaboine, D. Matovero, R.N. Rumanyika. Bizarre presentation of bilateral ovarian leiomyoma: a case report. Tanzan J Health Res. 15 (2013), 259-261.

[23] T. Dworniak, P. Kaminski, M. Czaplicki, K. Szymanska, L. Marianowski. [Clarocellular carcinoma of the kidney in coexistence with ovarian leiomyoma]. GINEKOL POL. 73 (2002), 623-626.

[24] S. Kelekci, S. Eris, E. Demirel, S. Aydogmus, N. Ekinci. Lipoleiomyoma of the uterus and primary ovarian leiomyoma in a postmenopausal woman: two rare entities in the same individual. Case Rep Pathol. 2015 (2015), 564846.

[25] S. Kojiro, Y. Tomioka, Y. Takemoto, N. Nishida, T. Kamura, M. Kojiro. Primary leiomyoma of the ovary-a report of 2 resected cases. Kurume Med J. 50 (2003), 169-172.

[26] B. Khangar, V. Mallya, N. Khurana, P. Sachdeva, S. Kashyap. Coexisting leiomyomata peritonealis disseminata and ovarian leiomyoma. J Midlife Health. 8 (2017), 45-47.

[27] N. Khaffaf, H. Khaffaf, S. Wuketich. Giant ovarian leiomyoma as a rare cause of acute abdomen and hydronephrosis. OBSTET GYNECOL. 87 (1996), 872-873. 
[28] I. Bayram, S. Senol, S. Ozen, G.H. Sahin. Placental site trophoblastic tumor and concomitant primary ovarian leiomyoma in a postmenopausal woman. Am J Clin Oncol. 30 (2007), 97-98.

[29] C. Wei, N. Lilic, N. Shorter, E. Garrow. Primary ovarian leiomyoma: a rare cause of ovarian tumor in adolescence. J Pediatr Adolesc Gynecol. 21 (2008), 33-36.

[30] D. Tomas, T. Lenicek, N. Tuckar, Z. Puljiz, M. Ledinsky, B. Kruslin. Primary ovarian leiomyoma associated with endometriotic cyst presenting with symptoms of acute appendicitis: a case report. DIAGN PATHOL. 4 (2009), 25.

[31] M. Guney, M. Ozsoy, B. Oral, T. Mungan, N. Kapucuoglu. Unilateral primary ovarian leiomyoma in adolescent: a case report. ARCH GYNECOL OBSTET. 275 (2007), 507-510.

[32] A.F. Al-Shaikh, A. Darwish, V. Nagaraj, A. Alsada. A rare combination of ovarian and uterine leiomyomas with goblet cell carcinoid of the appendix. Case Rep Surg. 2015 (2015), 467243.

[33] S.C. Lim, H.J. Jeon. Bilateral primary ovarian leiomyoma in a young woman: case report and literature review. GYNECOL ONCOL. 95 (2004), 733-735.

[34] M.L. San, F. Londero, V. Stefanutti, L. Costa, M. Rocco. Ovarian leiomyoma. Case report. Clin Exp Obstet Gynecol. 18 (1991), 145-148.

[35] A.E. Yumru, M. Bozkurt, Y.T. Ayanoglu, I. Ayhan, C.E. Inci, H.S. Battal. The relation between the presence of a giant primary ovarian leiomyoma and the occurrence of epilepsy as a paraneoplastic syndrome. ARCH GYNECOL OBSTET. 281 (2010), 531-534.

[36] P. Seinera, M. Raspollini, S. Privitera, C. Farina, F. Crana. Bilateral ovarian leiomyoma. Acta Obstet Gynecol Scand. 76 (1997), 488-489.

[37] Y. Akizawa, T. Miyashita, R. Sasaki, R. Nagata, R. Aoki, K. Ishitani, Y. Nagashima, H. Matsui, K. Saito. Gorlin syndrome with an ovarian leiomyoma associated with a PTCH1 second hit. AM J MED GENET A. 170A (2016), 1029-1034.

[38] A.I. Guzel, A. Yalinkaya, M. Alomeroglu. A rare case of acute abdomen: torsionated ovarian myoma. J Exp Ther Oncol. 10 (2014), 255-257.

[39] M. Kim, C. Lee, J. Ko, H. Choi, Y. Cho, K. Chun. Torsion of Ovarian Leiomyoma in a Woman With 10 Weeks' Gestation. J Minim Invasive Gynecol. 22 (2015), S201-S202.

[40] C.G. Zorlu, S. Cengiz, H.O. Harmanli. Primary ovarian leiomyoma. A case report. Gynecol Obstet Invest. 36 (1993), 191-192.

[41] Y. Daniel, J.B. Lessing, A. Bar-Am, M.J. Kupferminc, J. Jossiphov, M.R. Peyser. Treatment of bilateral multiple primary ovarian leiomyomas during pregnancy by way of conservative surgery: a case report. Eur 
J Obstet Gynecol Reprod Biol. 74 (1997), 125-126.

[42] C.H. Hsiao, H.C. Wang, S.L. Chang. Ovarian leiomyoma in a pregnant woman. Taiwan J Obstet Gynecol. 46 (2007), 311-313.

[43] N.R. Blue, J.C. Felix, J. Jaque. Primary ovarian leiomyoma in a premenarchal adolescent: first reported case. J Pediatr Adolesc Gynecol. 27 (2014), e87-e88.

[44] M. Guney, M. Ozsoy, B. Oral, T. Mungan, N. Kapucuoglu. Unilateral primary ovarian leiomyoma in adolescent: a case report. ARCH GYNECOL OBSTET. 275 (2007), 507-510.

[45] S. Sudhamani, D. Agrawal, A. Pandit, V.M. Kiri. Lipoleiomyoma of uterus: a case report with review of literature. Indian J Pathol Microbiol. 53 (2010), 840-841.

[46] B. Ghosh, B. McKeown, A. Gumma. Lipoleiomyoma. BMJ Case Rep. 2011 (2011).

[47] Y.J. Koo, Y.J. Cho, J.Y. Kim, J.E. Lee, M.L. Kim, J.M. Kim, H.W. Han, K.Y. Joo. Ovarian leiomyoma as a potential cause of compromised fertility. FERTIL STERIL. 95 (2011), 1111-1120.

[48] B.J. Doss, S.M. Wanek, S.M. Jacques, F. Qureshi, N.C. Ramirez, W.D. Lawrence. Ovarian leiomyomas: clinicopathologic features in fifteen cases. INT J GYNECOL PATHOL. 18 (1999), 63-68.

[49] D. Tomas, T. Lenicek, N. Tuckar, Z. Puljiz, M. Ledinsky, B. Kruslin. Primary ovarian leiomyoma associated with endometriotic cyst presenting with symptoms of acute appendicitis: a case report. DIAGN PATHOL. 4 (2009), 25.

[50] R. Agrawal, M. Kumar, L. Agrawal, K.K. Agrawal. A huge primary ovarian leiomyoma with degenerative changes-an unusual. J Clin Diagn Res. 7 (2013), 1152-1154.

[51] I. Sanverdi, F. Vural, O. Temizkan, O. Temel, H. Ayvaci, P. Gunes. Primary ovarian leiomyoma in a postmenopausal woman: A case report. North Clin Istanb. 3 (2016), 222-224.

\section{Tables}

Due to technical limitations, the tables are only available as a download in the supplemental files section.

\section{Figures}



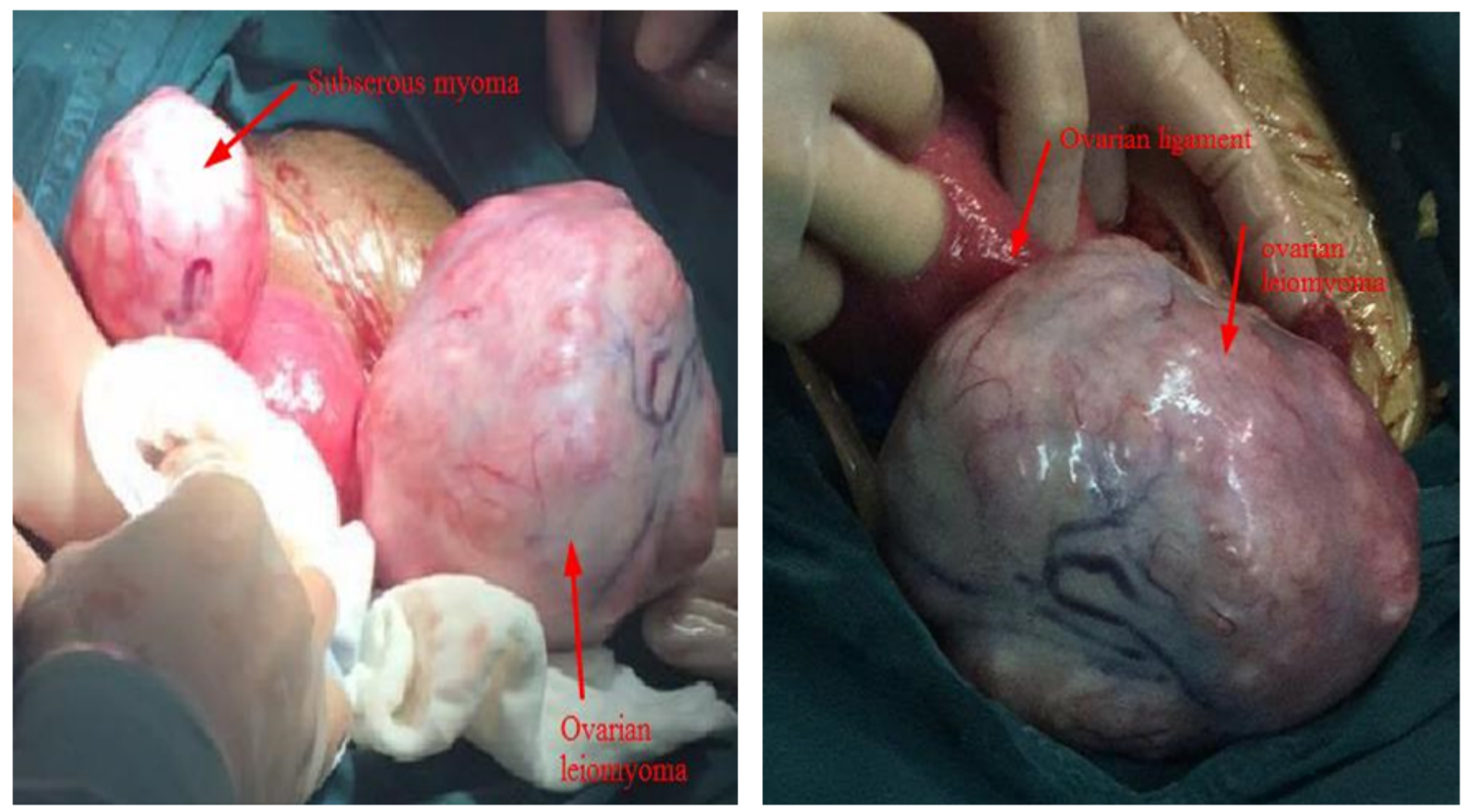

\section{Figure 1}

Transabdominal intraoperative view of case 8 the right ovary and part of the uterus with the left subserous myoma(left). The right ovary is noted to be enlarged with a $8 \mathrm{~cm}$ hard mass in diameter separated from the uterus not adherent to or infiltrating the surroundings(right) . 

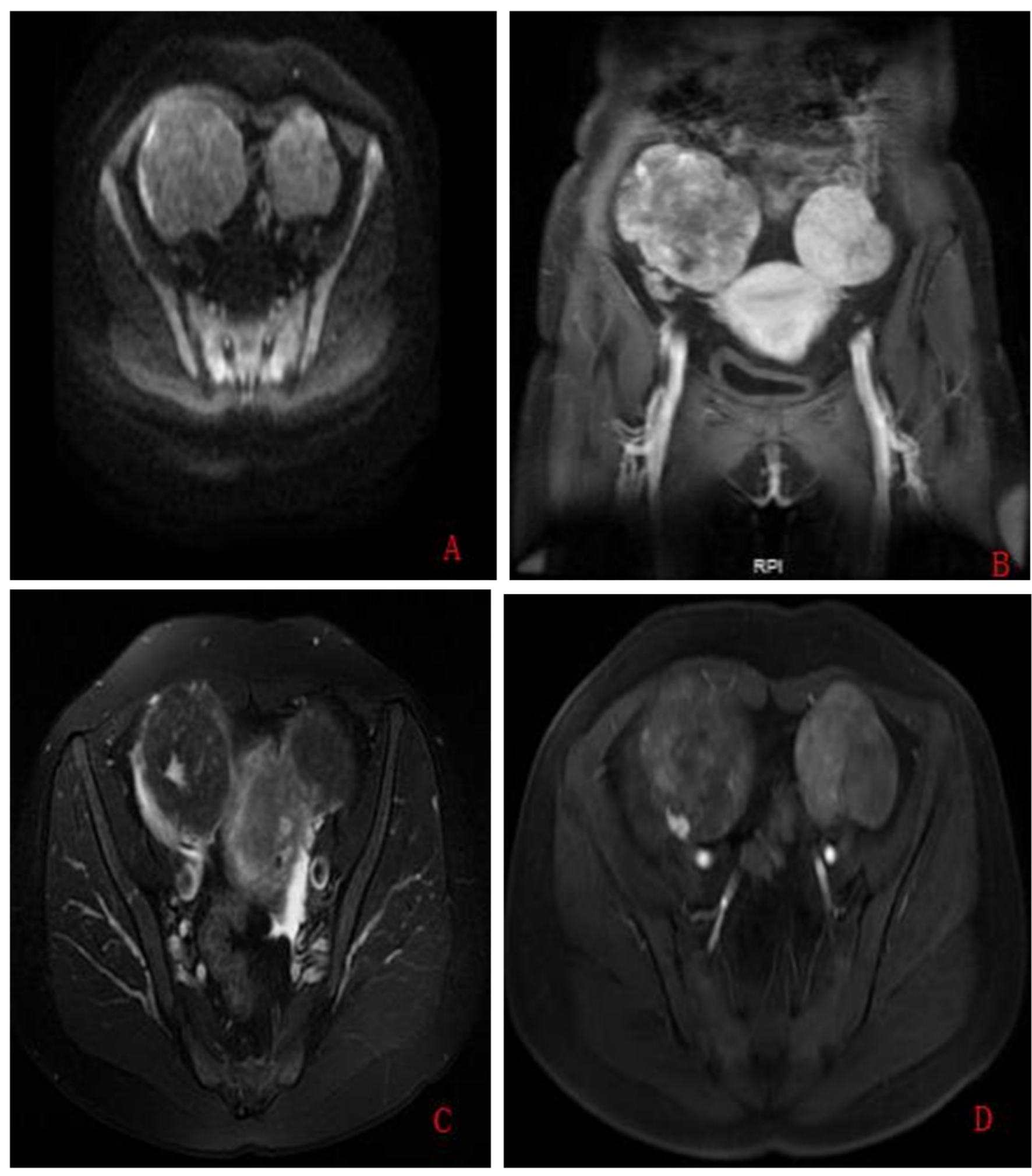

\section{Figure 2}

Magnetic resonance imaging of the pelvis from case 8. On axial diffusion--weighted image(TR/TE: $4000 / 72.4 \mathrm{~ms}, \mathrm{~b}$ value $=500 \mathrm{~s} / \mathrm{mm} 2$ ) the two masses showed the same intermediate signal intensity $(A)$. On sagital T1-weighted with gadolinium administration(TR/TE:3.9/1.7ms) the left mass showed low

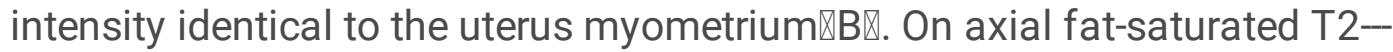

weighted(TR/TE:3020/70.5ms)image, the signal intensity of the left mass was continued with the 
myometrium while the right mass was well-circumscribed and sharply demarcated from the uterus $\varangle \mathrm{C}$ ). On axial T1--weighted with gadolinium administration(TR/TE:3.9/1.7ms), flow voids could only be seen

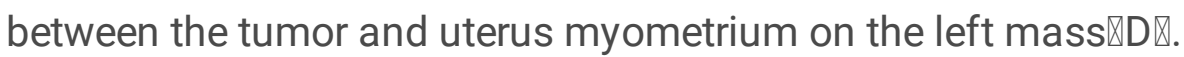
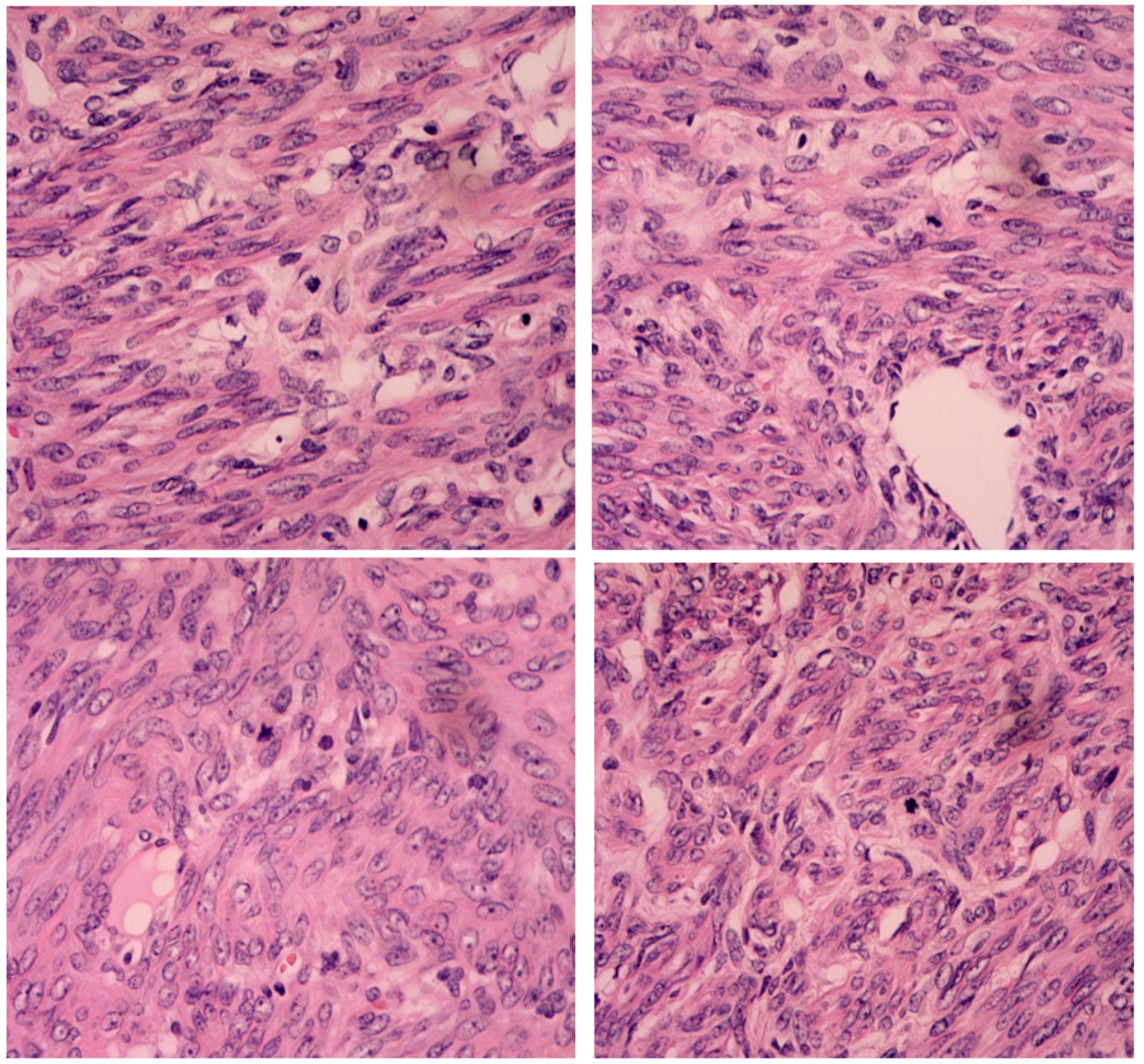

\section{Figure 3}

4 mitosis coulbd be found in very 10 high power field (HPF)from case $5(\mathrm{H} \& \mathrm{E} \times 400)$

\section{Supplementary Files}

This is a list of supplementary files associated with this preprint. Click to download. 
- Tables.docx

Page 13/13 